\title{
A Dual-Band Millimeter-Wave Microstrip Antenna Array for 5G Applications
}

\author{
G. Viswanadh Raviteja \\ Assistant Professor \\ Department of ECE \\ ANITS, Visakhapatnam, India
}

\begin{abstract}
In this paper, microstrip antenna array is discussed. The proposed antenna array is designed for millimeter-wave applications targeting the $24.25 \mathrm{GHz}$ to $27.5 \mathrm{GHz}$ and 26.5 $\mathrm{GHz}$ to $29.5 \mathrm{GHz}$ range of the frequency spectrum. The dielectric substrate considered is the Rogers RT Duroid 6002. Initially, a conventional antenna is designed and simulated. The basic design is studied first and then is subjected to the next stage in the design. A $2 \mathrm{X} 1$ microstrip antenna array is later evolved from the initial conventional design whose radiation characteristics are studied. Later stage, another $2 \mathrm{X} 1$ antenna array is connected, which makes the end structure a combination of two $2 \mathrm{X} 1$ microstrip antenna array connected back to back. The end result is a 4 element antenna array with dual-band characteristics with S11 parameter $-32.88 \mathrm{~dB}$ at $24.67 \mathrm{GHz}$ with a gain of $8.67 \mathrm{~dB}$ and $-35.07 \mathrm{~dB}$ at 29.35 $\mathrm{GHz}$ with a gain of $10.30 \mathrm{~dB}$. The end structure is compared with the initial and intermediate stage designs in terms of S11, gain and VSWR and important findings are tabulated.
\end{abstract}

\section{Keywords}

Millimeter-wave communications, dual-band antenna, 5G applications, mm-Wave.

\section{INTRODUCTION}

Vast changes and the increased use of mobile data are seen in the last decade. This tremendous increase in the usage of cellular communications and wireless applications led to the shortage of the available bandwidth which proved to be a serious issue for the service providers [1]. These cellular service providers have a limited range of carrier frequency spectrum to deliver multimedia and other applications for wireless systems [2]. The broadband cellular network providers need to cope with the truth that they need to understand the increasing demands for consumer data and traffic volumes. An improved and efficient wireless technology and wideband range of the spectrum is necessary to meet the needs of wireless carriers [3]. There is an overcrowded situation present in the sub- $3 \mathrm{GHz}$ spectrum and on the other side, the $3-300 \mathrm{GHz}$ frequency range is said to be under-utilized. The Super High Frequency (SHF) is the 3$30 \mathrm{GHz}$ range and the $30-300 \mathrm{GHz}$ is the Extremely High Frequency (EHF) range. The EHF is the millimeter-wave band. On the account of showing similar characteristics in terms of propagation in both the SHF and EHF band, the radio waves here are termed as millimeter-waves referring to 3 $300 \mathrm{GHz}$ as its band with wavelengths 1 to $100 \mathrm{~mm}$ [4]. The $5 \mathrm{G}$ systems will likely utilize in or near this underutilized spectrum ranging from $30-300 \mathrm{GHz}$. Because of the extremely small wavelengths, it is necessary to deploy highly directional antennas. On the other hand, these antennas should be able to steerable. Collectively these antennas should be used using novel methodologies [5]. One important point to mention is the lossy characteristics of mm-wave bands compared to the lower microwave frequencies. More reliable mm-wave channel modeling is necessary to mitigate or reduce the lossy conditions [6]. Because of the range of working is shifted to higher frequencies (24 to $86 \mathrm{GHz}$ ), the antennas designed should also have proper radiation characteristics. Multiband and ultra-wideband antennas with high directivity and efficiency are proved to very useful for 5G wireless communication systems [7]. In particular, the regions between 24 to $29.5 \mathrm{GHz}$ are mainly focused on $5 \mathrm{G}$ as this region offers lower attenuation and lower atmospheric absorptions compared to the higher range of frequencies [8]

\section{ANTENNA DESIGN STRUCTURE}

A Conventional antenna is designed in the first stage of the design process. The antenna is designed to resonate at 24 to $26 \mathrm{GHz}$ frequency range. The patch dimensions considered are $4.11 \times 3.23$ (in $\mathrm{mm}$ ) in terms of the width and length which are calculated using the patch antenna design calculations as mentioned in [9]. The substrate used is Rogers RT / Duroid 6002 with a dielectric constant of 2.94 and loss tangent 0.0012. The antenna is fed using strip-line feeding mechanism as shown in Figure 1.

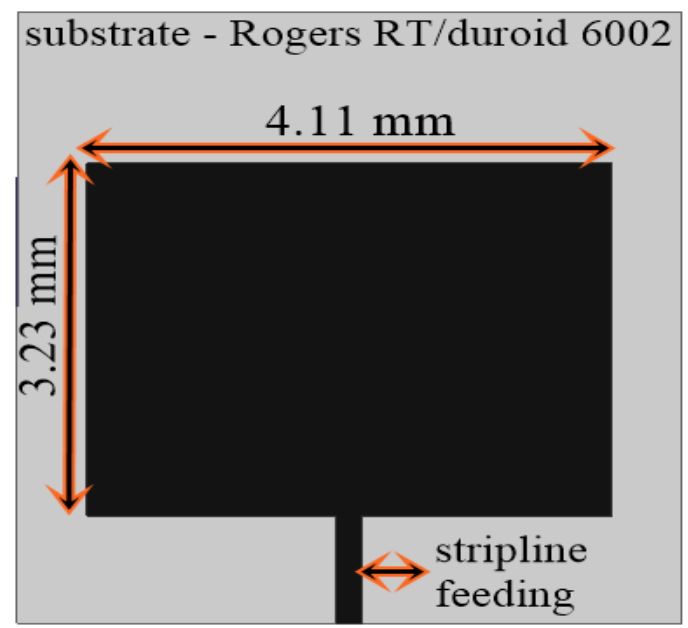

Figure 1. Conventional Antenna Design

The simulated results are discussed, with the S11 parameter being $-38.52 \mathrm{~dB}$ for a center frequency of $25.50 \mathrm{GHz}$ with VSWR calculated to be 1.024 . The gain for the conventional antenna is found to be $6.935 \mathrm{~dB}$ at $25.50 \mathrm{GHz}$. The $\mathrm{S} 11$, VSWR and gain plots of the conventional antenna are given in Figures 2, 3 and 4. 


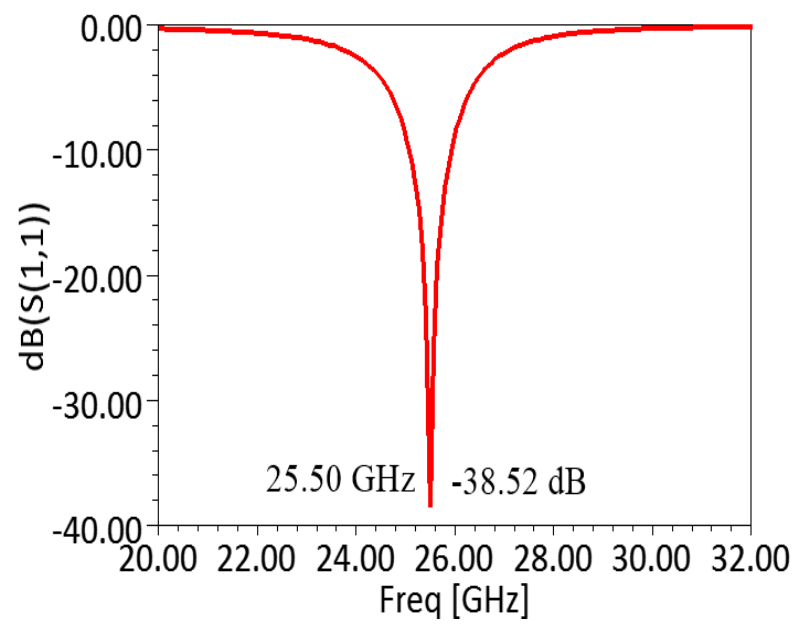

Figure 2. S11 plot for the conventional antenna

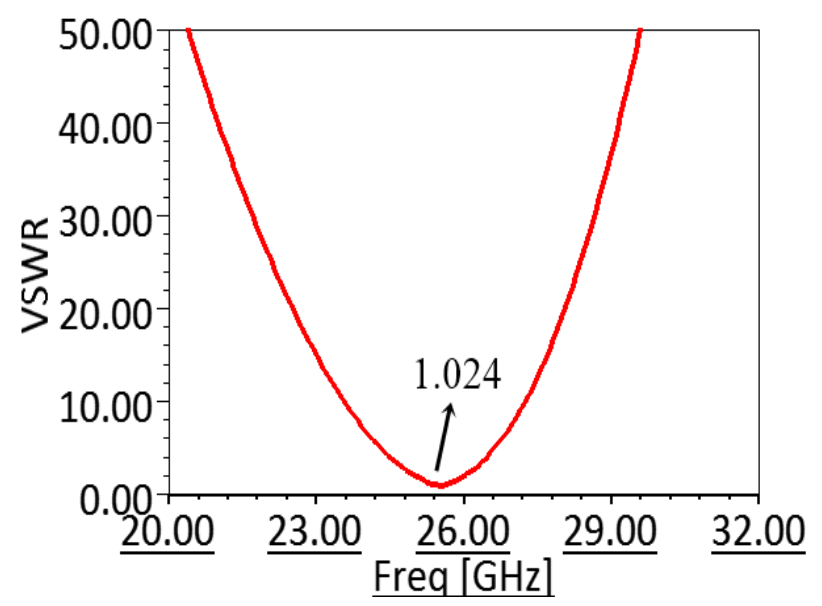

Figure 3. VSWR plot for the conventional antenna

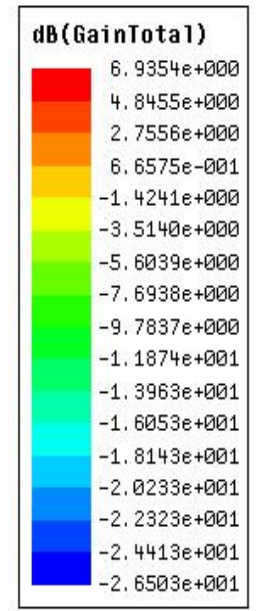

Figure 4. 3-dimensional gain plot for conventional antenna

\section{2X1 MICROSTRIP MILLIMETER- WAVE ANTENNA ARRAY}

The design is extended to array configuration post the simulation of the conventional antenna. A 2 X1 millimeterwave antenna array is realized with the same patch dimensions discussed for conventional antenna and be able to work in the 24 to $26 \mathrm{GHz}$ frequency range. The distance between the individual antenna is optimized to be ' $7 \mathrm{~mm}$ ' from the center of feed of each antenna element. The array configuration is shown in Figure 5

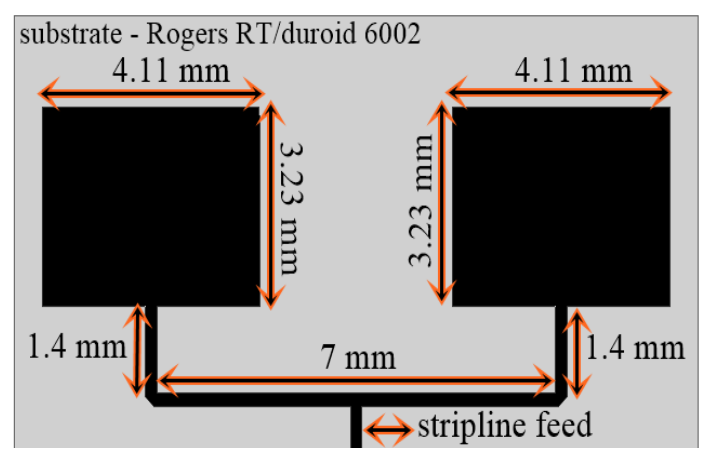

Figure 5. 2X1 microstrip millimeter-wave antenna array

The designed antenna array is simulated for computing the antenna parameters. The S11 plot for the $2 \mathrm{X} 1$ antenna array is found to be $-22.67 \mathrm{~dB}$ with a VSWR of 1.095 at a center frequency of $25.73 \mathrm{GHz}$. The gain for this array is found to be $9.60 \mathrm{~dB}$ with a more directional pattern. The results for S11, VSWR and gain plots are shown in Figures 6, 7 and 8.

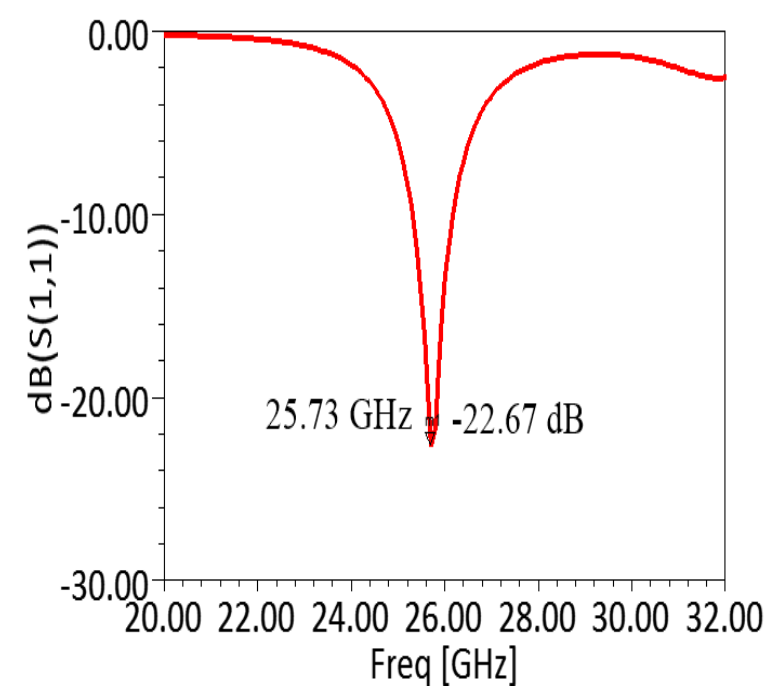

Figure 6. S11 plot for the $2 X 1$ antenna array

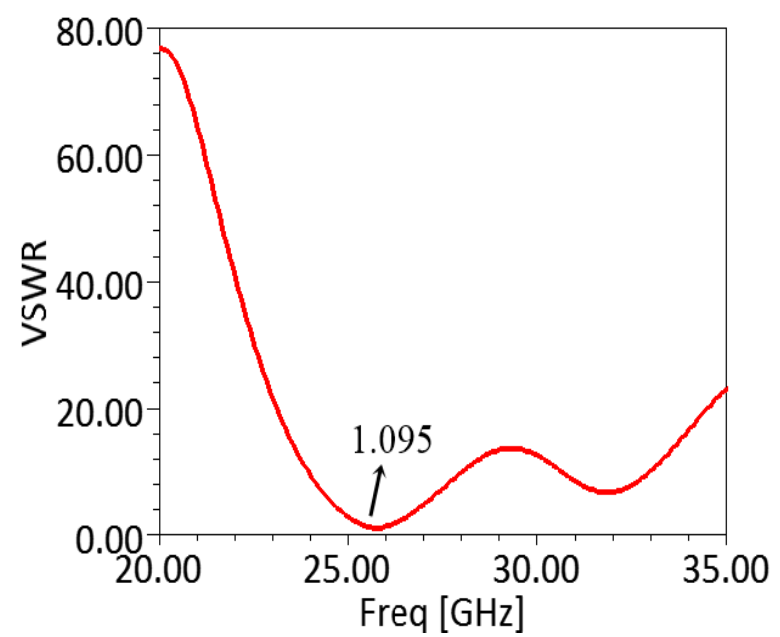

Figure 7. VSWR plot for the $2 X 1$ antenna array 

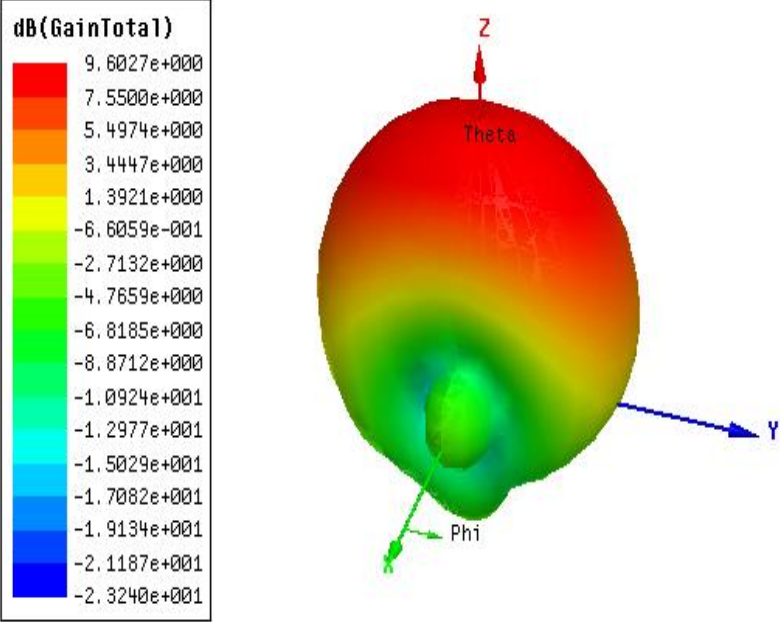

Figure 8. 3-dimensional gain plot the $2 \mathrm{X} 1$ antenna array

\section{4-ELEMENT DUAL BAND}

\section{MILLIMETER-WAVE ANTENNA}

\section{ARRAY}

As a final stage in the design process, a 4 element millimeterwave antenna array is designed. The array is designed to realize dual-band characteristics in the frequency range of 24 to $29.5 \mathrm{GHz}$. For this, to the initial $2 \mathrm{X} 1$ antenna array, another $2 \mathrm{X} 1$ antenna array in a flipped configuration is attached and a common feed point is given making the configuration look like two $2 \mathrm{X} 1$ antenna array connected back to back. The proposed array configuration is shown in Figure 9.

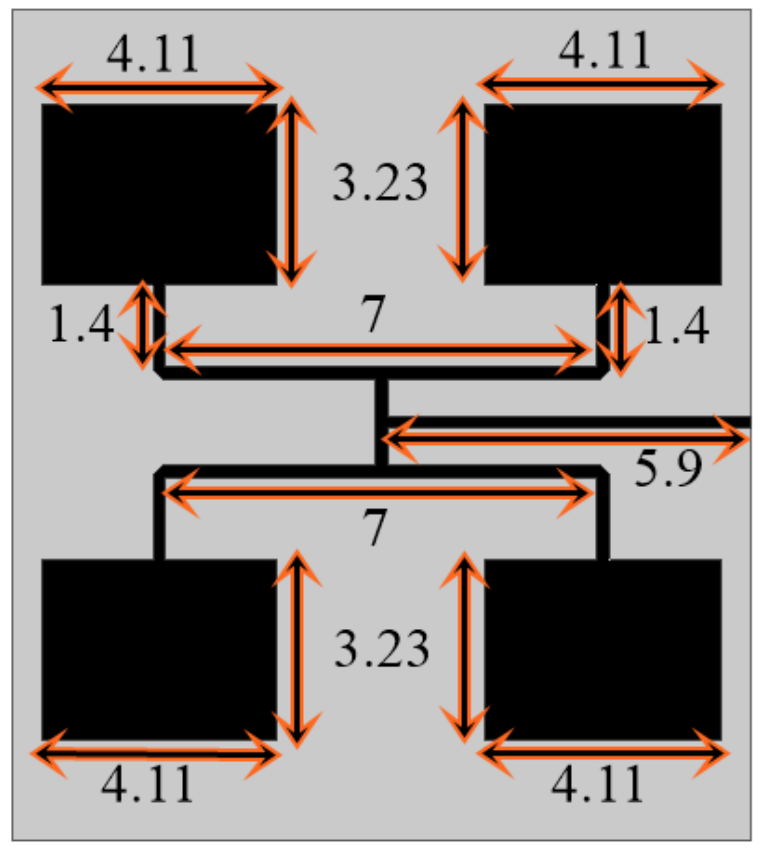

Figure 9. 4-Element Dual-band millimeter-wave antenna array

The designed antenna array configuration excited two frequency bands with improved radiation properties being more directional. The $\mathrm{S} 11$ parameter is found to be $-32.88 \mathrm{~dB}$ at a frequency of $24.67 \mathrm{GHz}$ and $-35.07 \mathrm{~dB}$ at a frequency of $29.35 \mathrm{GHz}$ with corresponding VSWR values of 1.046 and 1.035. The gain is also computed from the 3 -dimensional gain plot. The gain at $24.67 \mathrm{GHz}$ is found to be $8.67 \mathrm{~dB}$ and at
29.35 GHz it is $10.30 \mathrm{~dB}$. The S11, VSWR and gain plots are shown in Figures 10, 11, 12 and 13.

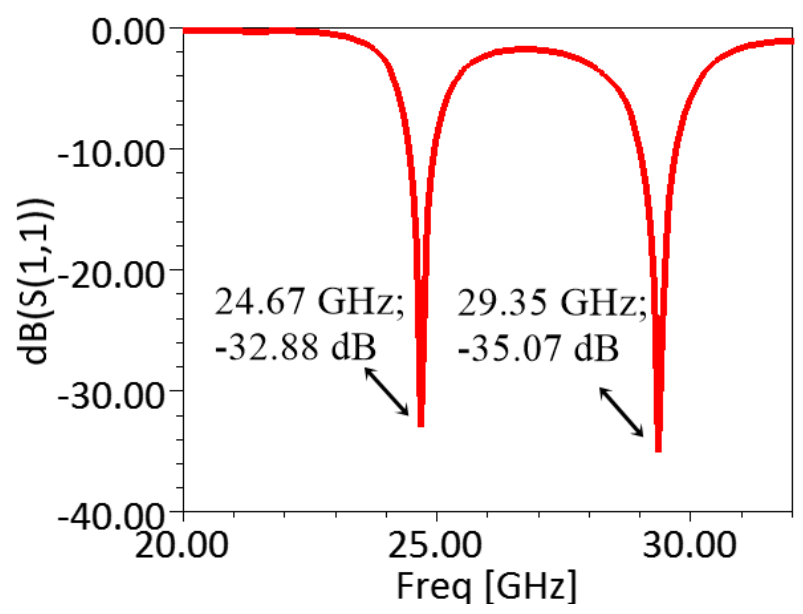

Figure 10. S11 plot for the 4-element antenna array

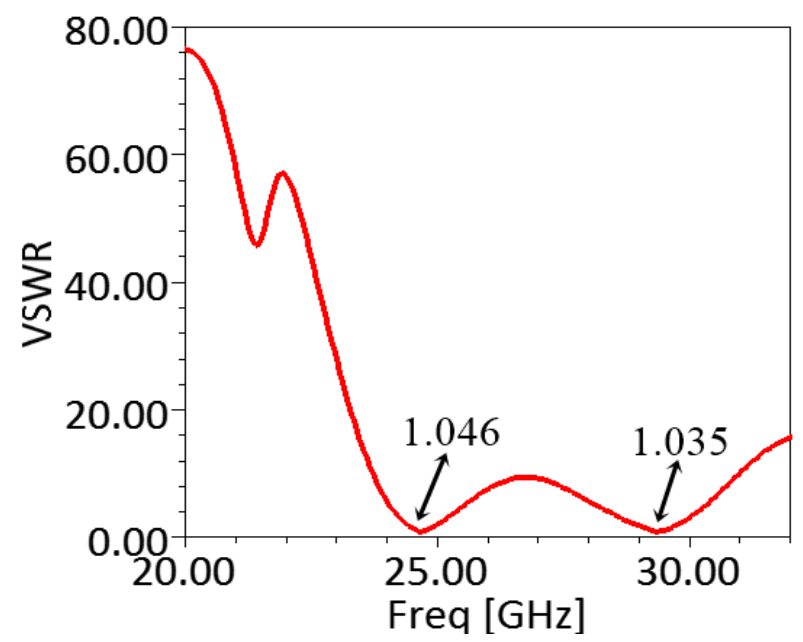

Figure 11. VSWR plot for the 4-element antenna array
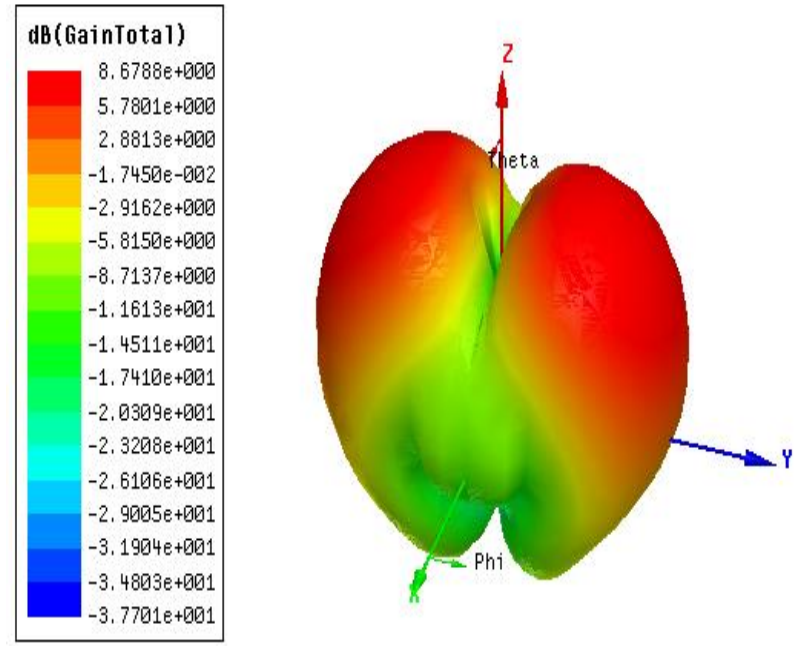

Figure 12. 3-dimensional gain plot at 24.67 GHz frequency 

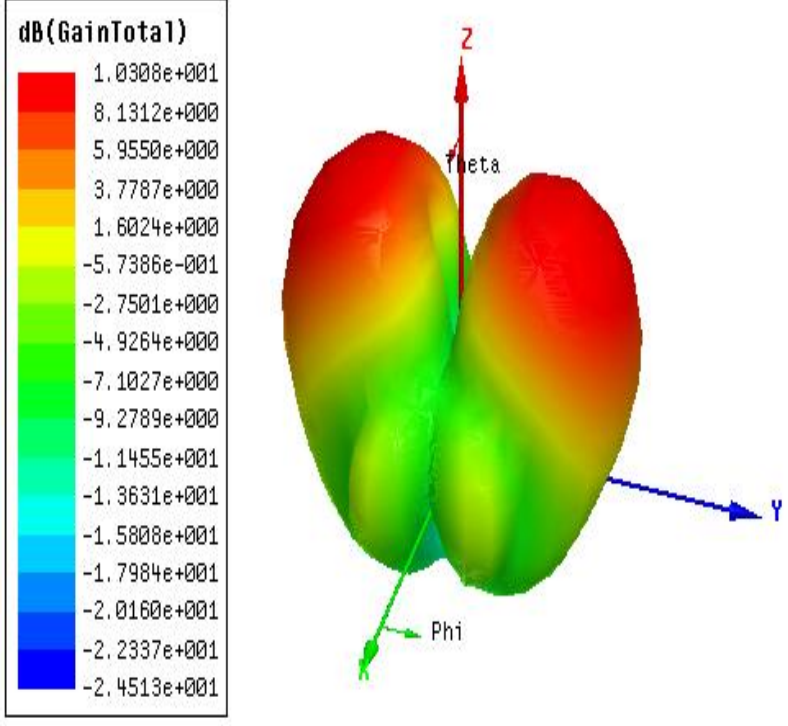

Figure 13. 3-dimensional gain plot at 29.34 GHz frequency

Table 1. Different characteristic parameters for the antenna structures considered

\begin{tabular}{|c|c|c|c|c|}
\hline $\begin{array}{c}\text { Antenna } \\
\text { Configuration }\end{array}$ & $\begin{array}{c}\text { Operating } \\
\text { Frequency } \\
\text { (GHz) }\end{array}$ & $\begin{array}{c}\text { S11 } \\
\text { (in dB) }\end{array}$ & VSWR & $\begin{array}{c}\text { Gain } \\
\text { (in dB) }\end{array}$ \\
\hline $\begin{array}{c}\text { Conventional } \\
\text { Antenna }\end{array}$ & $25.50 \mathrm{GHz}$ & -38.52 & 1.024 & 6.93 \\
\hline $\begin{array}{c}\text { X 1 Antenna } \\
\text { Array }\end{array}$ & $25.73 \mathrm{GHz}$ & -22.67 & 1.095 & 9.60 \\
\hline $\begin{array}{c}\text { Proposed 4 - } \\
\text { element }\end{array}$ & $24.67 \mathrm{GHz}$ & -32.88 & 1.046 & 8.67 \\
Antenna Array & and & -35.07 & 1.035 & 10.30 \\
and & $29.35 \mathrm{GHz}$ & & \multicolumn{2}{|c|}{} \\
\hline
\end{tabular}

\section{CONCLUSION}

A 4 - element dual-band millimeter-wave microstrip antenna array is designed and simulated covering the $5 \mathrm{G}$ frequency bands 24 to $29.5 \mathrm{GHz}$. The designed antenna array, as expected, exhibited dual-band characteristics with an S11 value of $-32.88 \mathrm{~dB}$ at $24.67 \mathrm{GHz}$ and $-35.07 \mathrm{~dB}$ at a frequency of $29.35 \mathrm{GHz}$ with 1.046 and $1.035 \mathrm{VSWR}$ values. The gain, when computed, is found to be $8.67 \mathrm{~dB}$ at $-24.67 \mathrm{GHz}$ and $10.30 \mathrm{~dB}$ at $29.35 \mathrm{GHz}$. The pre-final versions of the proposed structure also showed good agreement with the taken frequency considerations. The conventional antenna showed up an S11 of $-38.52 \mathrm{~dB}$ at $25.50 \mathrm{GHz}$ with VSWR of 1.024 and gain value of $6.93 \mathrm{~dB}$, whereas for the $2 \mathrm{X} 1$ antenna array the S11 is $-22.67 \mathrm{~dB}$ at $25.73 \mathrm{GHz}$ with a VSWR of 1.095 and gain value of $9.60 \mathrm{~dB}$. Therefore, the proposed antenna array with dual-band characteristics resonating at $24.67 \mathrm{GHz}$ and $29.35 \mathrm{GHz}$ with a good directional gain of $8.97 \mathrm{~dB}$ and $10.30 \mathrm{~dB}$ can be extensively used as mm-Wave antenna array for $5 \mathrm{G}$ applications.

\section{REFERENCES}

[1] El-Bacha, A. and Sarkis, R., 2016, September. Design of tilted taper slot antenna for $5 \mathrm{G}$ base station antenna circular array. In 2016 IEEE Middle East Conference on Antennas and Propagation (MECAP) (pp. 1-4). IEEE.

[2] Gupta, P., 2013. Evolvement of mobile generations: 1G to 5G. International Journal for Technological Research in Engineering, 1, pp.152-157.3

[3] Rappaport, T.S., Sun, S., Mayzus, R., Zhao, H., Azar, Y., Wang, K., Wong, G.N., Schulz, J.K., Samimi, M. and Gutierrez, F., 2013. Millimeter wave mobile communications for $5 \mathrm{G}$ cellular: It will work!. IEEE access, 1, pp.335-349.

[4] Pi, Z. and Khan, F., 2011. An introduction to millimeterwave mobile broadband systems. IEEE communications magazine, 49(6), pp.101-107.

[5] Sulyman, A.I., Nassar, A.T., Samimi, M.K., MacCartney, G.R., Rappaport, T.S. and Alsanie, A., 2014. Radio propagation path loss models for $5 \mathrm{G}$ cellular networks in the $28 \mathrm{GHz}$ and $38 \mathrm{GHz}$ millimeter-wave bands. IEEE Communications Magazine, 52(9), pp.7886.

[6] Rappaport, T.S., Gutierrez, F., Ben-Dor, E., Murdock, J.N., Qiao, Y. and Tamir, J.I., 2012. Broadband millimeter-wave propagation measurements and models using adaptive-beam antennas for outdoor urban cellular communications. IEEE transactions on antennas and propagation, 61(4), pp.1850-1859.

[7] Ioannis, G. and Katherine, S., 2018, May. Design of ultra wide band slot antennas for future $5 \mathrm{G}$ mobile communication applications. In 2018 7th International Conference on Modern Circuits and Systems Technologies (MOCAST) (pp. 1-4). IEEE.

[8] Jilani, S.F. and Alomainy, A., 2017, July. Millimeterwave conformal antenna array for $5 \mathrm{G}$ wireless applications. In 2017 IEEE International Symposium on Antennas and Propagation \& USNC/URSI National Radio Science Meeting (pp. 1439-1440). IEEE.

[9] Srivastava, S., Singh, V.K., Singh, A.K. and Ali, Z., 2013. Duo triangle shaped microstrip patch antenna analysis for WiMAX lower band application. Procedia Technology, 10, pp.554-563. 